\title{
Do Night Shifts Increase the Risk of Benign Paroxysmal Positional Vertigo Among Doctors and Nurses?
}

This article was published in the following Dove Press journal: Journal of Multidisciplinary Healthcare

\section{Khalid Bashir Hamdy Hamed Elsotohy Amr Elmoheen (D)}

Emergency Department, Hamad General Hospital, Hamad Medical Corporation Doha, Qatar
Correspondence: Amr Elmoheen Hamad Medical Corporation, Emergency Department, Hamad General Hospital, PO Box: 3050, Doha, Qatar Email Aelmoheen@hamad.qa
Background: Night shift work is one of the significant and most frequent reasons for circadian rhythm disruptions, resulting in the alteration of biological functions and sleep. These factors can affect the psychological and physical well-being and also negatively impact an individual's performance at work. Sleep disturbance has been associated with increased risk of several medical conditions such as benign paroxysmal positional vertigo (BPPV), hypertension, diabetes, high cholesterol, chronic obstructive pulmonary disease, and others.

Objective: To determine whether the night shift increases the risk of BPPV by reviewing a 7-year retrospective data.

Methods: The cross-sectional research study was conducted at the emergency department of a tertiary care teaching hospital in Qatar. A total of 69 doctors and nurses who suffered from vertigo in a period of seven years were consented and considered for the study. We excluded 12 patients with vertigo due to causes rather than BPPV. Fifty-seven patients who were diagnosed with BPPV based on examination using the Dix-Hallpike bedside test. They were treated by particle repositioning maneuvers in the emergency department.

Results: Approximately, 93\% $(n=53)$ of participants had posterior canal BPPV and 7\% $(n=4)$ had lateral canal BPPV $(n=5)$ between 2013 and 2019. Anterior canal BPPV was not reported. Chi-square test showed that night shift was associated with a high prevalence of first BPPV episode ( $P \geq 0.001)$ with less likelihood of diabetes and hypertension $(P \geq 0.001)$. Conclusion: Retrospective data review indicates a possible association between night shifts and BPPV development in doctors and nurses.

Keywords: benign paroxysmal vertigo, doctors, nurses, night shift

\section{Introduction}

Working night shifts disturbs the circadian rhythm and may be detrimental to the health of the workers. ${ }^{1}$ Night shifts are necessary for the hospital environment for continuity of care for patients. Nearly half of night workers complain of sleep disturbances. ${ }^{1}$ Sleep disturbance has been associated with increased risk of several medical conditions such as benign paroxysmal positional vertigo (BPPV), hypertension, diabetes, high cholesterol level, chronic obstructive pulmonary disease, and others. ${ }^{2}$

BPPV is a medical condition characterized by brief episodic attacks of vertigo accompanied by spinning sensation with certain head movements. It is slightly more common in middle-aged women than men with a lifetime prevalence of $2.4 \%{ }^{3}$ The wellaccepted model explaining the pathophysiology of BPPV is known as "canalolithiasis," 
in which vertigo is caused by abnormal stimulation of the cupula through free-floating calcium particles "otoconia" in the semicircular canals migrated from the utricle. BPPV is a disabling condition and can cause physical and mental stress and may lead to poor performance. ${ }^{4}$ BPPV can be reliably diagnosed with bedside tests and effectively treated by several head rotation maneuvers usually performed in an office or a clinic. ${ }^{4}$ Radiological imaging or blood test is normally not required for its diagnosis and treatment. ${ }^{4}$ Approximately $20 \%$ of patients may have a recurrence of vertigo symptoms in the first year. ${ }^{5}$ Several risk factors for the development of BPPV have been reported in the literature, such as trauma, metabolic disorders, old age, sleep disturbances, mental health problems, osteoporosis, and vitamin D deficiency. ${ }^{5}$ Sleep deprivation can negatively affect human beings and has been shown to exacerbate several conditions, such as diabetes, renal disease, high blood pressure, and cerebrovascular accidents (CVA). ${ }^{6}$ Previous studies investigated the association between sleep disturbance and chronic dizziness, and approximately $2 / 3$ of patients with chronic dizziness suffer from sleep disturbance. ${ }^{7,8}$ Based on our literature review, no study has investigated the association between night duties and BPPV among doctors and nurses (D\&N).

This study aimed to explore whether night duties increase the risk of BPPV among D\&N by reviewing the retrospective data in the last seven years.

\section{Materials and Methods}

This study was conducted at the emergency department of a large tertiary care teaching hospital in Doha, the capital of the state of Qatar. The study center sees approximately 0.5 million patients every year. Therefore, there are thousands of employed doctors and nurses (D\&Ns); most of them are obliged to work in Day and Night shifts. The study was approved by the Institutional Review Board (IRB) of the host hospital (MRC 01-20-182). A study sample of a total of 69 doctors and nurses who work in the emergency or other departments who suffered from vertigo in a period of seven years. We excluded patients over 60 years, history of recent head trauma, or history of neurological diseases, including migraine, old stroke, or central diseases. The patients included in the study used to contact one emergency physician $(\mathrm{KB})$ with specific interests in vertigo management. Fifty-seven patients who were diagnosed with BPPV based on the history of brief periods of movement or spinning sensation with changes in the position of the head and by examination using the Dix-Hallpike bedside test. They were treated by particle repositioning maneuvers in the emergency
Table I Comparison of Data in the Group with Symptoms That Started After a Night Duty

\begin{tabular}{|l|l|l|l|}
\hline Characteristics & $\begin{array}{l}\text { BPPV* Started } \\
\text { After Night } \\
\text { Duty, n = 37 }\end{array}$ & $\begin{array}{l}\text { BPPV* Did Not } \\
\text { Start After Night } \\
\text { Duty, n = 20 }\end{array}$ & P-value \\
\hline $\begin{array}{l}\text { Male } \\
\text { Female }\end{array}$ & $\begin{array}{l}23(62.2 \%) \\
14(37.8 \%)\end{array}$ & $\begin{array}{l}13(65 \%) \\
7(35 \%)\end{array}$ & $\mathrm{P}<0.533$ \\
\hline $\begin{array}{l}\text { Doctor } \\
\text { Nurse }\end{array}$ & $\begin{array}{l}8(21.6 \%) \\
29(78.4 \%)\end{array}$ & $\begin{array}{l}15(75 \%) \\
5(25 \%)\end{array}$ & $\mathrm{P}<0.000 \mathrm{I}$ \\
\hline $\begin{array}{l}\text { Right } \\
\text { Left }\end{array}$ & $\begin{array}{l}22(59.5 \%) \\
15(40.5 \%)\end{array}$ & $\begin{array}{l}12(60 \%) \\
8(40 \%)\end{array}$ & $\mathrm{P}<0.598$ \\
\hline $\begin{array}{l}\text { Posterior canal } \\
\text { Lateral canal }\end{array}$ & $\begin{array}{l}36(97.3 \%) \\
(2.7 \%)\end{array}$ & $\begin{array}{l}17(85 \%) \\
3(15 \%)\end{array}$ & $\mathrm{P}<0.119$ \\
\hline $\begin{array}{l}\text { First episode of } \\
\text { BPPV* } \\
\text { Diabetes mellitus }\end{array}$ & $36(97.3 \%)$ & $12(60 \%)$ & $\mathrm{P}<0.00 \mathrm{P}$ \\
\hline Hypertension & $3(8.1 \%)$ & $2(10 \%)$ & 0.58 \\
\hline
\end{tabular}

Abbreviation: *BBPV, benign paroxysmal positional vertigo.

department. Other patients $(\mathrm{n}=12)$ with negative bedside tests were excluded and referred to either neurology or balance clinics. A cross-sectional research design was employed. Anonymized data were collected (Table 1) using an Excel sheet. Data were analyzed using the statistical software SPSS (statistical software version 22.0) and using correlation analysis and chi-square tests. $P$-value at 0.05 was used to determine the test significance.

\section{Results}

In the last 7 years (2013-2019), 57 D\&N were diagnosed and treated with BPPV in the emergency department of Hamad General Hospital by one emergency physician (KB). Among them, $40.4 \%(n=23)$ were doctors and $59.6 \%(\mathrm{n}=34)$ were nurses, comprising $63.2 \%(\mathrm{n}=36)$ male $36.8 \%(n=21)$ female patients. About $87.7 \%(n=50)$ of patients aged $>40$ years and $12.3 \%(n=7)$ aged $<40$ years. Approximately $93 \%(\mathrm{n}=53)$ of participants were diagnosed with posterior canal BPPV and $7 \%(n=4)$ with lateral canal BPPV $(n=5)$. No case of anterior canal BPPV was found in this study. The right ear was affected in 59.6\% $(\mathrm{n}=34)$ and the left ear was involved in $40.4 \%(\mathrm{n}=23)$. No participant suffered a recent trauma. Whereas, 35.1\% $(\mathrm{n}=20)$ had other pre-existing conditions: $7 \%(\mathrm{n}=4)$ had diabetes and $8.8 \%(\mathrm{n}=5)$ had hypertension.

Of all 57 patients enrolled in our study, there were $64.9 \%(n=37)$ of patients complained of vertigo that 
started after the night duty. $35.1 \%(n=20)$ of patients had vertigo, which was not related to night duty.

Approximately $84.2 \%(n=48)$ of patients experienced BPPV for the first time. The remaining $15.8 \%(n=9)$ had suffered from previous episodes of vertigo. From the patients complained of vertigo that started after the night duty, there were $97.3 \%(n=36)$ developed BPPV for the first time. On the other hand, D\&N, who suffered vertigo, which was not related to night duty $(n=20)$, only $60 \%(n=12)$ encountered the first episode of vertigo.

Chi-square test showed that night duty was associated with a high prevalence of the first BPPV episode ( $>$ 0.001). Participants were less likely to have hypertension and diabetes $(\mathrm{P}>0.001)$.

\section{Discussion}

Sleep disturbance, hypertension, and diabetes are associated with chronic dizziness among the general population. The findings of this study showed that working at night shifts among D\&N may be a risk factor for the development of new-onset BPPV. In contrast to previously published studies, having diabetes and hypertension do not increase the risk of BPPV among healthcare professionals.

Poorly controlled hypertension and diabetes have been considered as potential risk factors for BPPV, particularly recurrent episodes, ${ }^{9}$ due to vestibular ischemia leading to shedding of otoconia from the utricle to semicircular canals. ${ }^{10}$ Our study indicated that D\&N with hypertension and diabetes were less likely to develop BPPV. One possible justification is that healthcare professionals have better knowledge on the management of chronic illness; hence, the risk of developing complications such as BPPV is low.

Sleep quality disturbance has been associated with the occurrence of BPPV, Meniere's disease, and psychogenic dizziness. Therefore, sleep quality should be considered in all patients presenting with dizziness symptoms. ${ }^{11}$ The impact of working at night shifts on the BPPV development remains unclear; however, one plausible explanation is the disturbance of the normal circadian rhythm that may lead to poor quality sleep and vestibular system stress, which may lead to BPPV development. ${ }^{12}$

The majority of patients included in this study suffer from posterior canal BPPV and less likely to suffer from lateral canal BPPV., ${ }^{4,13}$ These findings are consistent with our study results. Anterior canal BPPV is very rare; hence, no patient had anterior canal BPPV in this study. BPPV is found to be more common in the right ear, which is again consistent with our study results. Majority of patients who developed BPPV aged $>40$ years in this study, which is comparable with that of published literature. Trauma is a recognized factor for up to $10 \%$ of patients, ${ }^{4}$ and no patients in this study suffered trauma before the BPPV development.

\section{Limitations}

This study has several limitations. First, this is a retrospective study and thereby generally provide an inferior level of evidence compared with prospective studies. Bias may possibly occur during the data collection. Second, only hypertension, diabetes, trauma, and night shift were asked during the initial assessment. Other risk factors such as low vitamin D level, which is prevalent in the gulf area and Qatar, ${ }^{14} \mathrm{CVA}$, vestibular neuritis, or ear disease may exist, ${ }^{10}$ which were not asked. Third, sleep quality, a recognized risk factor of BPPV, was not asked in detail; instead, only night shift status was asked. A preferred option would have been a semi-structured interview, which was not possible in this retrospective study. Fourth, trauma was not asked in more detail, as some patients do not consider minor trauma as significant.

Despite the results of our study, further research on the relationship between night shifts and BPPV development should be conducted among healthcare professionals.

\section{Conclusions}

The retrospective data review indicates a possible association between night shifts and the development of newonset BPPV in D\&N. In contrast to previously published studies, having diabetes and hypertension does not increase the risk of BPPV among D\&N.

\section{Abbreviations}

BPPV, benign paroxysmal positional vertigo; CVA, cerebrovascular accidents; D\&N, doctors and nurses; OSAS, obstructive sleep apnoea syndrome.

\section{Funding}

Open Access funding provided by the Qatar National Library.

\section{Disclosure}

The authors report no conflicts of interest for this work.

\section{References}

1. Boughattas W, Maalel O E, Ben CR, et al. Hospital night shift and its effects on the quality of sleep, the quality of life, and vigilance troubles among nurses. Int $J$ Clin Med. 2014;05(10):572-583. doi:10.4236/ijcm.2014.510079 
2. Shih $\mathrm{CP}$, Wang $\mathrm{CH}$, Chung $\mathrm{CH}$, et al. Increased risk of benign paroxysmal positional vertigo in patients with non-apnea sleep disorders: a nationwide, population-based cohort study. J Clin Sleep Med. 2018;14(12):2021-2029. doi:10.5664/jcsm.7528

3. Von Brevern M, Seelig T, Radtke A, Tiel-Wilck K, Neuhauser H, Lempert T. Short-term efficacy of Epley's manoeuvre: a double-blind randomised trial. $J$ Neurol Neurosurg Psychiatry. 2006;77 (8):980-982. doi:10.1136/jnnp.2005.085894

4. Bhattacharyya N, Gubbels SP, Schwartz SR, et al. Clinical practice guideline: benign paroxysmal positional vertigo (update). Otolaryngol Head Neck Surg. 2017;156(3):S1-S47. doi:10.1177/ 0194599816689667

5. Zhu CT, Zhao XQ, Ju Y, Wang Y, Chen MM, Cui Y. Clinical characteristics and risk factors for the recurrence of benign paroxysmal positional vertigo. Front Neurol. 2019;10. doi:10.3389/ fneur.2019.01190

6. Nakada T, Sugiura S, Uchida Y, Suzuki H, Teranishi M, Sone M. Difference in serum levels of vitamin $\mathrm{D}$ between canalolithiasis and cupulolithiasis of the horizontal semicircular canal in benign paroxysmal positional vertigo. Front Neurol. 2019;10.

7. Wang Y, Xia F, Wang WHW, Hu W. Assessment of sleep quality in benign paroxysmal positional vertigo recurrence. Int $J$ Neurosci. 2018;128(11):1143-1149. doi:10.1080/00207454.2018.1486835
8. Sugaya N, Arai M, Goto F. The effect of sleep disturbance in patients with chronic dizziness. Acta Otolaryngol. 2017;137(1):47-52. doi:10.1080/00016489.2016.1213418

9. Lopes AR, Moreira MD, Trelha CS. De Moraes Marchiori LL. Association between complaints of dizziness and hypertension in non-institutionalized elders. Int Arch Otorhinolaryngol. 2013;17 (2):157-162. doi:10.7162/S1809-97772013000200007

10. Picciotti PM, Lucidi D, De Corso E, Meucci D, Sergi B, Paludetti G. Comorbidities and recurrence of benign paroxysmal positional vertigo: personal experience. Int $J$ Audiol. 2016;55(5):279-284. doi:10.3109/14992027.2016.1143981

11. Kim SK, Kim JH, Jeon SS, Hong SM. Relationship between sleep quality and dizziness. PLoS One. 2018;13(3):1-10.

12. Gallina S, Dispenza F, Kulamarva G, Riggio F, Speciale R. Obstructive sleep apnoea syndrome (OSAS): effects on the vestibular system. Acta Otorhinolaryngol Ital. 2010;30(6):281-284.

13. Kim JS, Zee DS. Benign paroxysmal positional vertigo. $N$ Engl J Med. 2014;370(12):1138-1147. doi:10.1056/NEJMcp1309481

14. Badawi A, Arora P, Sadoun E, Al-Thani AA, Thani MH. Prevalence of vitamin d insufficiency in Qatar: a systematic review. J Public Health Res. 2012;1(3):229-235. doi:10.4081/jphr.2012.e36
Journal of Multidisciplinary Healthcare

\section{Publish your work in this journal}

The Journal of Multidisciplinary Healthcare is an international, peerreviewed open-access journal that aims to represent and publish research in healthcare areas delivered by practitioners of different disciplines. This includes studies and reviews conducted by multidisciplinary teams as well as research which evaluates the results or conduct of such teams or healthcare processes in general. The journal

\section{Dovepress}

covers a very wide range of areas and welcomes submissions from practitioners at all levels, from all over the world. The manuscript management system is completely online and includes a very quick and fair peer-review system. Visit http://www.dovepress.com/testimonials. php to read real quotes from published authors. 